\title{
Crack initiation and fatigue behaviour evaluation of ceramic film deposited on Ti-6Al-4V alloy
}

\author{
Md. Shamimur Rahman, Md. Abdullah Al Mahmood \\ Rajshahi University of Engineering \& Technology (RUET), Rajshahi-6204, Bangladesh \\ Email address: \\ msrahman92@yahoo.com (M. S. Rahman), abdullah2038@yahoo.com (M. A. Al Mahmood)
}

\section{To cite this article:}

Md. Shamimur Rahman, Md. Abdullah Al Mahmood. Crack Initiation and Fatigue Behaviour Evaluation of Ceramic Film Deposited on Ti-6Al-4V Alloy. International Journal of Materials Science and Applications. Vol. 3, No. 5, 2014, pp. $246-249$. doi: $10.11648 /$ j.ijmsa.20140305.25

\begin{abstract}
Titanium alloy offers several material properties including strength-to-weight ratio and good fatigue properties. Wear resistance of Titanium alloy is comparatively lower. To improve its wear resistant properties surface treatment must be considered. Hard thin film deposited by PVD technique is well-known to improve the wear resistance. In this study, ceramic film $(\mathrm{CrN})$ was applied to titanium alloy and its effect on the fatigue behavior was investigated. Substrate material for this work was Ti-6Al-4V. As the film hardness, crystal orientation and surface morphology were strongly depended on the bias voltage during the deposition, the ceramic film was deposited by arc ion plating (AIP) method at two different negative bias voltages. Tension-tension fatigue test and tensile test were carried out to investigate the fatigue properties. As the result, the fatigue strength was influenced by the deposition of the ceramic film, especially; the fatigue strength was remarkably decreased by the deposition of the ceramic film at high negative bias voltage compared to the uncoated specimen and the deposition of the ceramic at low negative bias voltage. On the basis of crack initiating behavior during fatigue test and tensile test the difference of the fatigue strength was also investigated.
\end{abstract}

Keywords: Titanium Alloy, Crack Initiation, Ceramic Film, Fatigue

\section{Introduction}

The beneficial effect of thin ceramic coatings deposited by PVD technique is well-known in terms of improvement in wear resistance, corrosion resistance and selecting the proper surface film material. On the other hand; any coating system giving improved wear properties may drastically reduce the fatigue life of a component due to cracks starting in the coating and propagating into the substrate material. Considering, for instance, chrome-plate parts, they show improved wear behavior but, also, a shorter fatigue life with respect to those of uncoated parts [1].

Strength-to-weight ratio and good corrosion resistances are the most desirable properties of a material. Titanium alloys have those properties. For this reason, this is frequently used for the aerospace industry, such as helicopter rotor hub arms and biomedical devices [2-4]. However, titanium alloy is easy to cause seizure and has very poor wear resistance; therefore, surface treatments should be applied when the contact parts are made from titanium alloy [5-6].
Physical vapor deposition (PVD) and nitriding are well-known surface treatment methods to improve the surface properties of titanium alloy. In particular, PVD coatings indicate high wear resistance, low coefficient of friction and seizure resistance; therefore, the coatings are widely used for tools etc. Chromium nitride ( $\mathrm{CrN})$ film is one of the film materials to improve wear and corrosion resistance [7-9].

The fatigue strength is influenced by the deposition of a hard thin film. In some cases, the fatigue life of a component reduces due to cracks initiating from the brittle film and propagating into the substrate material. For instance, $\mathrm{CrN}$ coatings show good wear behavior but they also show shorter fatigue life than that of uncoated parts [10-12]. In addition, some researchers pointed out that the fatigue strength decreased by the hard thin film coating where the surface hard film cracks in multiple points due to the impossibility to sustain the imposed strain [13]. The cracks, which are generated during cyclic loading, cause reduction 
of fatigue strength as well as decrease of wear, oxidation and corrosion resistance. To keep or improve the fatigue strength of the PVD coatings, it is important to increase the cracking stress of the film. As a possibility to solve this problem, control of film hardness might be effective.

In this study, $\mathrm{CrN}$ film was deposited on titanium alloy under the condition of high and low bias voltage by arc ion plating (AIP) method and the influence of film hardness on the fatigue strength of the coatings and the crack initiation behavior were investigated. Applied voltages were $V_{B}=$ $-20 \mathrm{~V}$ and $\mathrm{V}_{\mathrm{B}}=-300 \mathrm{~V}$. For these two voltages different parameters were investigated.

\section{Experimental Procedure}

The substrate material was (Ti-6Al-4V) which was heat treated at $740^{\circ} \mathrm{C}$ and furnace cooled. The chemical composition of this material is $0.01 \% \mathrm{C}, 4.20 \% \mathrm{~V}, 6.07 \%$ $\mathrm{Al}, 0.16 \% \mathrm{O}, 0.01 \% \mathrm{~N}, 0.16 \% \mathrm{~F}$ and $0.001 \% \mathrm{H}$, respectively. The material was machined into the shape as shown in Fig. 1 and the specimen surface was finished by polishing using \#150 \#1500 emery papers and $0.3 \mu \mathrm{m}$ alumina powder. Then, annealing was carried out at $650{ }^{\circ} \mathrm{C}$ in vacuum for 1 hour and furnace cooled. The 0.2 proof stress and tensile strength was $915 \mathrm{MPa}$ and $1065 \mathrm{MPa}$, respectively.

Ceramic film was deposited using AIP system (AIP-201, Kobe Steel Co.). The specimen was cleaned by ion bombardment process in nitrogen at gas flow rate of 53 sccm employing a voltage bias of $700 \mathrm{~V}$ and an arc current of $60 \mathrm{~A}$ for $1 \mathrm{~min}$, then $2 \mu \mathrm{m}$ thick $\mathrm{CrN}$ film was deposited by controlling the deposition time. Table 1 shows the coating process parameter. In this study, two different bias voltages of $\mathrm{V}_{\mathrm{B}}=-20 \mathrm{~V}$ and $-300 \mathrm{~V}$ were adopted to obtain different film surface. Hardness of the substrate and $\mathrm{CrN}$ film were measured using Vickers hardness tester (MVK-E3).

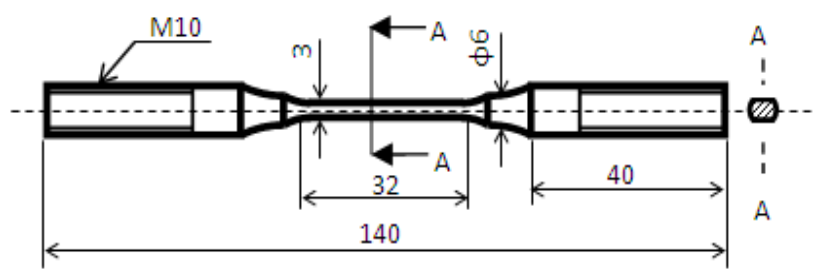

Fig 1. Fatigue test specimen configurations

Cracking of the $\mathrm{CrN}$ film was observed in this study conducted by replica method. The replica method is a way to observe the progress of surface crack and the occurrence of non-destructive under test. To do so, stopping the fatigue test at some point, the polymer film was transcribed into the shape summarized as in Fig. 2 immersed in organic solvent a few seconds, the polymer films pasted that melted the surface under test, and from the dried peel by which it is possible to check the progress of surface crack under test by observing the film.

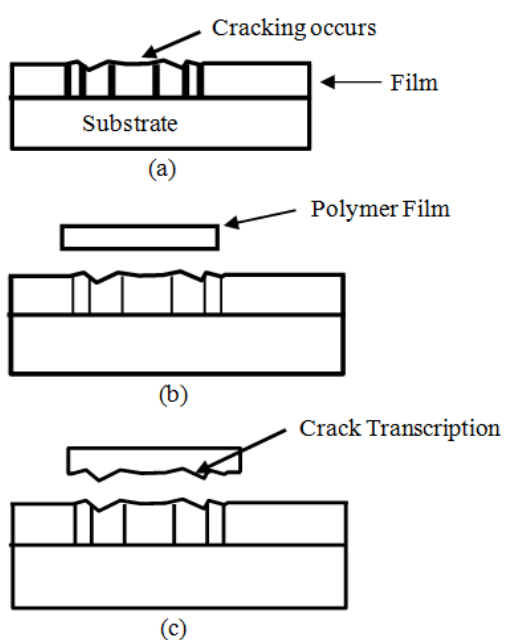

Fig 2. Schematic diagram of the replica method

By using a dynamic servo fatigue test machine (EFH-100) under load controlled condition at a frequency $10 \mathrm{~Hz}$ and stress ratio $\mathrm{R}=0.05$ tension-tension fatigue tests were carried out. The maximum of fatigue testing cycles was $10^{7}$ cycles. The fracture surfaces was observed using a scanning electron microscope (TM-1000).The cracks in the film surface were observed in situ using replica method at a various intervals during the test and the crack initiation stress was measured under tensile and cyclic loading.

Table 1. CrN coating condition

\begin{tabular}{ll}
\hline Bias voltage & $-20 \mathrm{~V},-300 \mathrm{~V}$ \\
Arc current & $50 \mathrm{~A}$ \\
Pressure & $5.33 \mathrm{~Pa}$ \\
Heater temperature & $573 \mathrm{~K}$ \\
Film thickness & $2.0 \mu \mathrm{m}$ \\
\hline
\end{tabular}

\section{Results and Discussions}

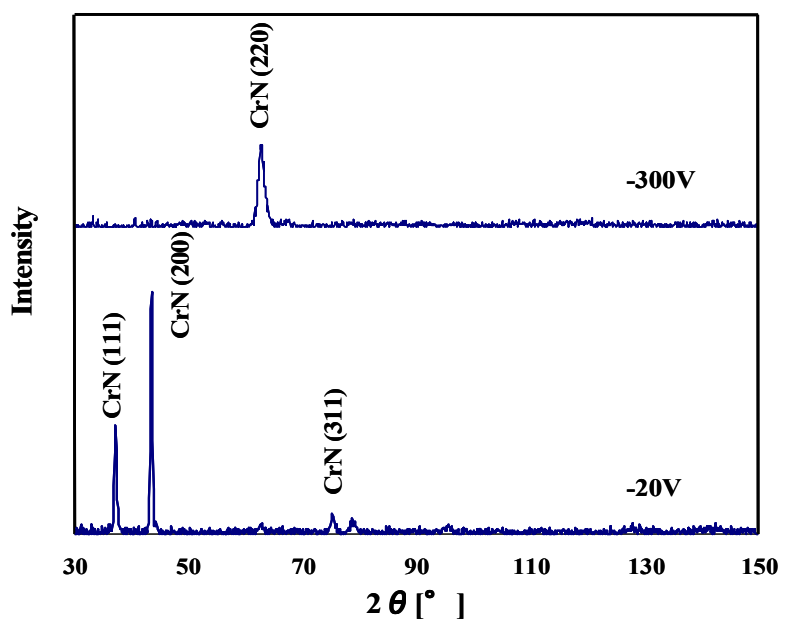

Fig 3. X-ray diffraction spectra of CrN coatings

The microstructure of the films was examined by X-ray diffraction. Fig. 3 shows the XRD spectra of the coatings deposited under $\mathrm{V}_{\mathrm{B}}=-20 \mathrm{~V}$ and $-300 \mathrm{~V}$. The film deposited 
under low bias voltage consisted of CrN (111), (200), and (311) which was random crystal orientation. In contrast with this, the film deposited under high bias voltage produced a different spectrum. The spectrum of high bias voltage film showed $\mathrm{CrN}$ (220) preferred orientation with a peak of very low intensity. There were no peaks of $\mathrm{CrN}$ (111), (200) and (311).

Based on these results, the peak residual stress measurement angle (CrN (311) plane for LB and $\mathrm{CrN}$ (220) plane for $\mathrm{HB}$ ) were using. Parameters used to measure residual stress were for $\mathrm{V}_{\mathrm{B}}=-20 \mathrm{~V} ; \mathrm{E}=230.4 \mathrm{GPa}, v=0.3$, $\theta_{0}=66.52^{\circ}$, and for $\mathrm{V}_{\mathrm{B}}=-300 \mathrm{~V} ; \mathrm{E}=292.7 \mathrm{GPa}, v=0.3, \theta_{0}$ $=51.46^{\circ}$. The measured residual stresses in $\mathrm{CrN}$ films for LB specimen and for HB specimen are shown in Table 2, which indicates that the specimens were of large compressive residual stress. Since uncoated specimens did not show any peak, residual stress could not be measured.

The as-deposited $\mathrm{Cr}-\mathrm{N}$ coatings under various bias voltages are of compressive residual stress. The stress increased initially and then decreased with the increasing of the bias voltage. The compressive stress arises when the coating is bombarded by ions with energies of tens or hundreds of eV through a process of atomic penning [2-3]. However, further increasing the energies of bombarding ion can result in lattice relaxation and recrystallization. According to Davis's model [4], the residual stresses can be relaxed by the thermal spikes, which results in the release of strain caused by the atomic penning effect. Therefore, the residual stress decreases at higher bias voltages.

Table 2. Film properties at sample surfaces

\begin{tabular}{llll}
\hline & Uncoated & \multicolumn{2}{c}{ CrN coated sample } \\
\cline { 3 - 4 } & sample & $\mathbf{V}_{\mathbf{B}}=\mathbf{- 2 0 V}$ & $\mathbf{V}_{\mathbf{B}}=-\mathbf{3 0 0 V}$ \\
\hline $\begin{array}{l}\text { Vickers Hardness }(\mathrm{HV}) \\
\text { Residual stress(GPa) }\end{array}$ & 328 & 1344 & 2408 \\
$\begin{array}{l}\text { Surface Roughness. }\left(\mathrm{R}_{\mathrm{a}}\right) \\
(\mu \mathrm{m})\end{array}$ & 0.08 & $-3.95 \pm 0.06$ & $-2.38 \pm 0.06$ \\
\hline
\end{tabular}

Hardness test was carried out to measure the surface hardness and was obtained by 30 points average. The hardness was $328 \mathrm{HV}$ for uncoated specimen, $1344 \mathrm{HV}$ for $\mathrm{V}_{\mathrm{B}}=-20 \mathrm{~V}$ and $2408 \mathrm{HV}$ for $\mathrm{V}_{\mathrm{B}}=-300 \mathrm{~V}$, respectively. It was found that the hardness of $\mathrm{CrN}$ films was strongly dependant on the bias voltage during the deposition and the film for high bias voltage specimen was higher than for low bias voltage sample.

Fatigue test was carried out under load controlled condition. The test was uni-axial tension-tension fatigue test. Fig. 4(a) shows the results of fatigue tests for uncoated titanium alloy specimens and the $\mathrm{CrN}$ coated specimens. The fatigue strength of the titanium alloy was changed by the deposition of $\mathrm{CrN}$ film and was influenced by the bias voltage during the deposition. In the case of the high bias voltage specimen $\left(V_{B}=-300 \mathrm{~V}\right)$, the fatigue strength was decreased by deposition. The effect was especially remarkable in the low maximum stress region which was less than $s_{\max }=650 \mathrm{MPa}$. But in the region of high maximum stress, the fatigue life of the titanium alloy was similar or slightly increased

The fatigue strength at $10^{7}$ cycles was changed by the deposition of $\mathrm{CrN}$ film. The fatigue strength for $\mathrm{V}_{\mathrm{B}}=-20 \mathrm{~V}$ was similar to uncoated specimen and slightly increase in low cycles region. However, fatigue strength for $V_{B}=-300$ $\mathrm{V}$ clearly decreased compared with uncoated and low bias voltage specimens. The difference of the fatigue strength of these coatings was approximately $200 \mathrm{MPa}$. A typical fracture surface was observed by SEM (Fig. 4 (b)) and it was confirmed that the fracture started from the surface for all specimens.

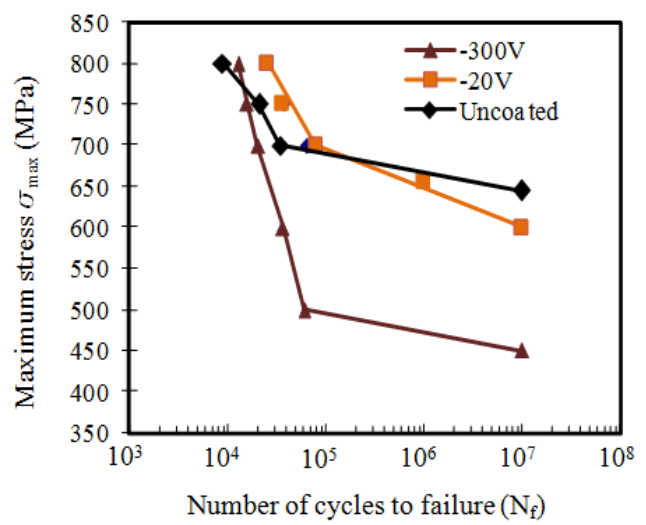

(a)
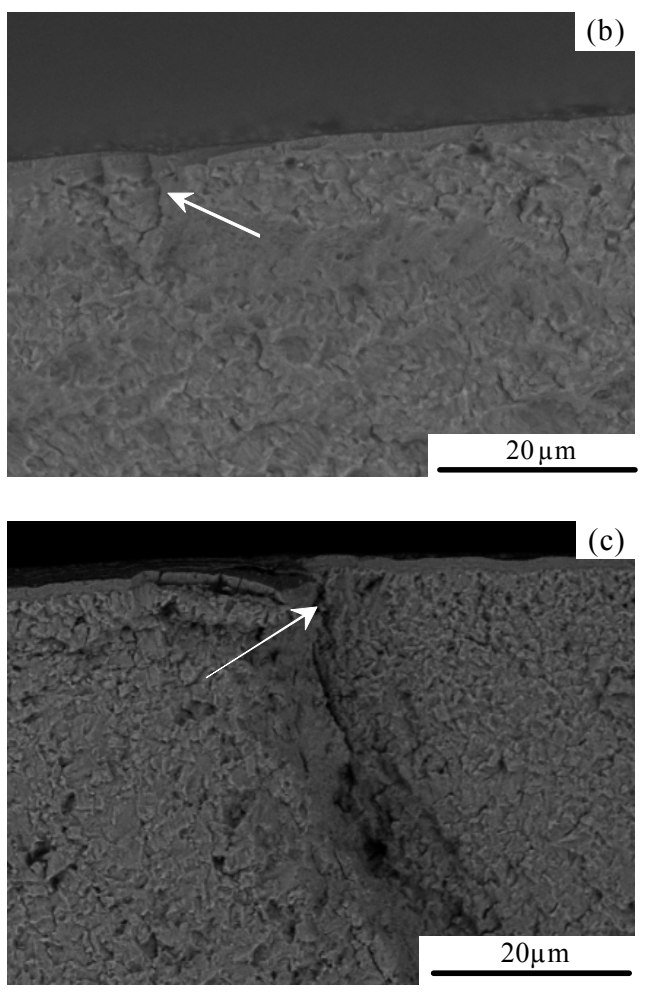

Fig 4. Result of fatigue tests: (a) S-N curves, and (b) and (c) Typical SEM image of fracture surface $\left(V_{B}=-20 \mathrm{~V}, \sigma_{\max }=800 \mathrm{MPa}, N_{f}=2.5 \times 10^{4} \mathrm{cycles}\right)$

To investigate the effect of bias voltage on crack initiation strength, successive observation of film surface was performed under tensile and cyclic loading by replica method. The result was summarized in Table 3. For tensile 
loading, crack was firstly observed at $700 \mathrm{MPa}$ for $\mathrm{V}_{\mathrm{B}}=$ $-20 \mathrm{~V}$ and at $625 \mathrm{MPa}$ for $\mathrm{V}_{\mathrm{B}}=-300 \mathrm{~V}$, respectively. The crack initiation stresses under tensile loading were clearly higher than the fatigue strength at $10^{7}$ cycles for each bias voltage and the stress for $\mathrm{V}_{\mathrm{B}}=-300 \mathrm{~V}$ was lower than for $\mathrm{V}_{\mathrm{B}}=-20 \mathrm{~V}$. For cyclic loading, cracks were observed above $625 \mathrm{MPa}$ for $\mathrm{V}_{\mathrm{B}}=-20 \mathrm{~V}$ and above $400 \mathrm{MPa}$ for $\mathrm{V}_{\mathrm{B}}=-300 \mathrm{~V}$ until $10^{6}$ cycles.

Table 3. Tensile and cyclic loading test of crack initiation stress of $\mathrm{CrN}$ films.

\begin{tabular}{llll}
\hline \multicolumn{2}{l}{ Crack initiation stress } \\
\hline \multirow{2}{*}{$\mathbf{V}_{\mathbf{B}}$} & Tensile loading & $\begin{array}{l}\text { Cyclic loading } \\
\text { [MPa] }\end{array}$ & $\begin{array}{l}\text { Fatigue strength at } \\
\mathbf{1 M P a}\end{array}$ \\
\hline$-20 \mathrm{~V}$ & 700 & 625 & 650 \\
$-300 \mathrm{~V}$ & 625 & 400 & 450 \\
\hline
\end{tabular}

The stresses were obviously lower than for tensile loading and were slightly lower than the fatigue strength at $10^{7}$ cycles. These results indicate that the fatigue strength of the coatings is determined by the cracks which are generated by cyclic loading. Ferreira has reported that hard film is too brittle to accommodate the substrate metal and the film fractured during the early stage of the fatigue process [14]. The film deposited at $\mathrm{V}_{\mathrm{B}}=-300 \mathrm{~V}$ has high hardness and will be more brittle. Although the film endures higher applied stress under tensile loading, the film cannot accommodate the substrate and fractured at lower cyclic stress than for tensile loading. In contrast, the film deposited at $\mathrm{V}_{\mathrm{B}}=-20 \mathrm{~V}$ may enable to endure the higher cyclic stress because the film will have more crack initiation resistance due to the lower hardness compared to the high bias voltage film. In conclusion, the difference of the fatigue strength is caused by the difference of the crack initiation stress which will be related to the film hardness.

At $10^{7}$ cycles $\mathrm{CrN}$ film cracking strength and fatigue strength has shown in Fig. 5. Two carves shown in the figure are for cyclic stress and static tensile stress. For different voltage at $\mathrm{V}_{\mathrm{B}}=-20 \mathrm{~V}$ and $\mathrm{V}_{\mathrm{B}}=-300 \mathrm{~V}$ cracking strength in $\mathrm{MPa}$ obtained, which has been shown by different color in the figure. From the Fig. 5 it is clear that cracking stress is higher for lower voltage.

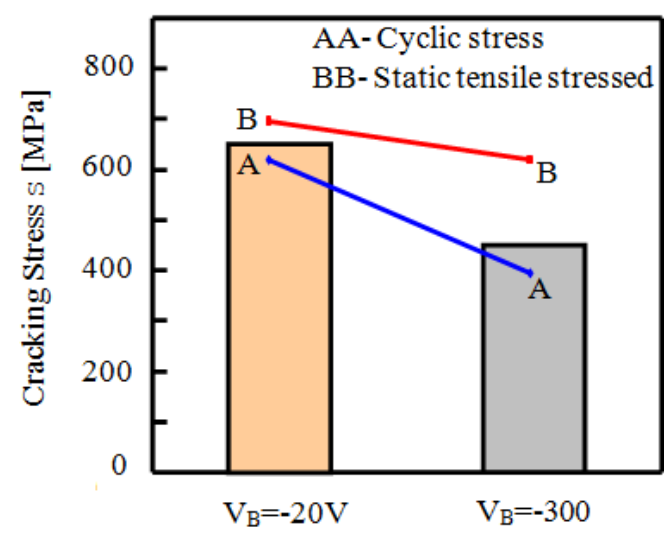

Fig 5. CrN film cracking strength and fatigue strength at $10^{7}$ cycles

\section{Conclusions}

The experiment was carried out to clarify the influence of bias voltage during deposition, the fatigue tests and tensile tests were carried out using the uncoated specimen and $\mathrm{CrN}$ coated specimens deposited at two different bias voltage. Followings are the summarized results:

(1) The fatigue strength and crack initiation stress of the film was strongly affected by the bias voltages during deposition.

(2) At $10^{7}$ cycles the fatigue strength was slightly increased by low negative bias voltage deposition compared to the uncoated specimen while the fatigue strength at $10^{7}$ cycles remarkable decreased by high bias voltage deposition.

(3) The crack initiation stress measurement indicated that the stress for high bias voltage film was clearly lower than for low bias voltage. This will be caused by the difference of brittleness due to the difference of film hardness.

\section{References}

[1] Ryuichiro Ebara, Masanori Fujimura, Tribology International, 391181 (2006).

[2] O. Jin, S. Mall, J.H. Sanders, S.K. Sharma, Surf. Coat. Technol., 2011704 (2006).

[3] Aravind Vadiraj, M. Kamaraj, Surf. Coat. Technol., 2004538 (2006).

[4] E. Bemporad, M. Sebastiani, D. De Felicis, F. Carassiti, R. Valle, F. Casadei, Thin Solid Films, 515186 (2006)

[5] L. Ceschini, E. Lanzoni, C. Martini, D. Prandstraller, G. Sambogna, Wear, 26486 (2008).

[6] I. Caron, R. Gras, T. Ganne, J.M. De Monicault, Tribology International, 391045 (2006).

[7] B. Navinsek, P. Panjan, Surf. Coat. Technol., 74 - 75919 (1995).

[8] J. Stockemer, R. Winand, P. Vanden Brande, Surf. Coat. Technol., 115230 (1999).

[9] M. Fenker, M. Balzer, H.A. Jehn, H. Kappl, J.-J. Lee, K.-H. Lee, H.-S. Park, Surf. Coat. Technol., 150101 (2002).

[10] A.D. Wilson, A. Leyland, A. Matthews, Surf. Coat. Technol., 11470 (1999).

[11] A. Wilson, A. Matthews, J. Housden, R. Turner and, B. Garside, Surf. Coat. Technol., 62600 (1993).

[12] S. Baragetti, G.M. La Vecchia, A. Terranova, Int. J. Fatigue, 271541 (2005).

[13] Nascimento MP., Souza RC., Pigatin WL., Voorwald HJC., Int. J. Fatigue, 23607 (2001).

[14] J. A. M. Ferreira, J. D. M Costa and V. Lapa, Int. J. Fatigue, 19293 (1997). 